\title{
Optimal Multiple-Steps Single-Tuned Harmonic Filters Under Time-Varying Conditions
}

\author{
S. H. E. Abdel Aleem \\ Member, IEEE \\ $15^{\text {th }}$ of May Higher \\ Institute of Engineering, \\ Cairo, Egypt \\ engyshady@ieee.org
}

\author{
A. F. Zobaa \\ Senior Member, IEEE \\ Brunel University London, \\ Uxbridge, Middlesex, UB8 \\ 3PH, U.K. \\ azobaa@ieee.org
}

\author{
A. M. Abdel Monem \\ Engineering Consultants Group, \\ Cairo, \\ Egypt \\ Ahmedabd_el_monem@hotmail.com
}

\author{
R. Kannan \\ Universiti Teknologi \\ Petronas, \\ Malaysia \\ kreee82@gmail.com
}

\begin{abstract}
Nowadays, considering the time-varying nature of harmonic sources is a significant trend in the power quality studies. In this research, the optimum sizing of multiple-steps passive LC compensator for maximum power factor and minimum transmission loss for non-linear loads under timevarying conditions of background harmonic voltages, system impedance, and load impedance, is determined. The source harmonic voltages are varying in time independently of each other. The equivalent system impedance is given by varying the Thevenin impedance over a finite period. The functioning of the concerned LC filter is explained through a representative case study. Simulation results illustrate the viability of the suggested approach.
\end{abstract}

Index Terms-- Passive filters, power factor correction, power system harmonics, power quality.

\section{INTRODUCTION}

Nature of electric loads has been changed because of the extensive use of the electronic components like diodes, thyristors, etc. Such non-linear loads have widespread use in our life either industrial or residential or commercial applications. The use of these elements raises the harmonic distortion level in the power system to higher level affecting the different quality of power indices such as the load power factor, the transmission loss and the transmission efficiency. Usually, consumers pay attention to the case when they experience poor power factor and directly pay in cash the price of their consumption with penalties or indirectly in technical problems caused by the inefficient performance of their equipment because of the operation in a distorted nonsinusoidal environment. Accordingly, much effort has been exerted to find a suitable solution which improving the power factor and reducing the losses in the transmission system, and at the same time absorbing the harmonic injected by the different non-linear loads and preventing them from reaching and affecting the electric utilities [1]-[7].

Basically, one of the solutions used to lessen the effect of harmonic distortion is the use of the shunt capacitor. However, resonance hazards may occur between the capacitor and the system impedance. This may cause an over-voltage and excessive current which may damage the capacitor itself or may shorten the lifetime expectancy of the types of equipment or degrade the overall power factor. Therefore, the tendency to use LC compensators has been necessary to provide the loads with enough kvar required to improve the power factor, or compensates the reactive power, and reduce the system transmission loss [8]-[10]. Usually, in its simplest form, a series combination of an inductor $L$ and capacitor $C$ is common.

The previous solution is based on some assumptions which simplify the design scheme; however, it may give capacitor values that do not meet the manufacturer's standard. Refs. [8][12] present some practical considerations for the choice of such LC compensator values for different design criteria taken into account the capacitor values in the power quality markets. Most of such studies did not give a concern to the timevarying nature of the background harmonic voltages, equivalent system impedance, and load impedance, and usually deal with them as fixed values, which may give a misleading configuration for the optimal LC compensator to achieve the desired criteria of design.

Ref. [13] reviews and summarizes the time-varying nature of the power system harmonics. The model that used to find the optimal LC compensator values based on the time variation of the source harmonic voltages, equivalent system impedance and load impedance can give an actual presentation for such situation. Refs. [14]-[16] assumes a particular timevariation for the equivalent system impedance where the outcomes of the connected shunt capacitances were taken into consideration.

In this work, an approach to find the optimal size of the inductive reactance $X_{\mathrm{L}}$ and the capacitive reactance $X_{\mathrm{C}}$ of a multiple-steps single-tuned passive compensator under timevarying conditions, is presented. The optimal compensator values will be able to mitigate the time-varying background harmonic voltages which are assumed to be independent of each other. The suggested design of the multiple-steps singletuned passive compensator considers a time-varying nature for both source and load impedance. Both the load power factor (PF) maximization and the transmission loss (TL) minimization are considered as objective functions. The IEEE Standard 18-2012 [17] based values for shunt-connected power capacitors are taken into account as non-linear constraints to give a viable and effective solution.

Finally, the operation of the concerned LC filter is described through a representative case study, primarily obtained from [18]. Simulation results illustrate the viability of the suggested approach. 


\section{Formulation OF THE PROBLEM}

Fig. 1 shows the configuration of the system under study, taking into account the background voltage harmonic components, represented by $V_{\mathrm{SK}}$ that affects a load bus, experiencing an additional current harmonic distortion because of the non-linear loads used. $I_{\mathrm{LK}}$ represents the nonlinear load currents represented by the current source model, where $K$ represents the harmonic order.

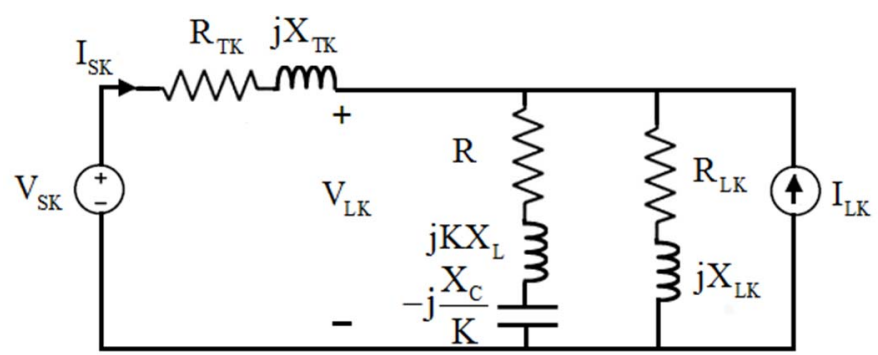

Fig. 1 Compensated time-varying non-linear load with non-sinusoidal supply

In order to derive the expressions of the $K$ th harmonic current $I_{\mathrm{SK}}$ and voltage $V_{\mathrm{LK}}$ at the non-linear load bus (PCC), one can define the following:

- $\quad$ The Thevenin voltage source realizing the mains as a function of time is given as,

$$
\mathrm{v}_{\mathrm{S}}(\mathrm{t})=\sum_{\mathrm{K}} \mathrm{v}_{\mathrm{SK}}(\mathrm{t})
$$

where $t$ is the time in seconds and $v_{S}$ is the source voltage in volts

- The Kth harmonic current realizing the non-linear load as a function of time is given as

$$
\mathrm{i}_{\mathrm{L}}(\mathrm{t})=\sum_{\mathrm{K}} \mathrm{i}_{\mathrm{LK}}(\mathrm{t})
$$

- The $K$ th harmonic time-variant source impedance $Z_{T K}$ is given as

$$
\mathrm{Z}_{\mathrm{TK}}=\mathrm{R}_{\mathrm{TK}}+\mathrm{j} \mathrm{X}_{\mathrm{TK}}
$$

where $R_{T K}$ and $X_{T K}$ are the $K$ th harmonic resistance and reactance of the harmonic Thevenin impedance, respectively. Both are given in ohms.

- $\quad$ The $K$ th harmonic time-variant load impedance $Z_{L K}$ and admittance $Y_{L K}$ are prearranged as

$$
\begin{aligned}
& Z_{\mathrm{LK}}=\mathrm{R}_{\mathrm{LK}}+\mathrm{j} \mathrm{X}_{\mathrm{LK}} \\
& \mathrm{Y}_{\mathrm{LK}}=\mathrm{G}_{\mathrm{LK}}-\mathrm{j} \mathrm{B}_{\mathrm{LK}}
\end{aligned}
$$

where $R_{L K}$ and $G_{L K}$ are the $K$ th harmonic load resistance in ohms and conductance in mhos, respectively. $X_{L K}$ and $B_{L K}$ are the $K$ th harmonic load reactance in ohms and susceptance in siemens, respectively.

- The Kth harmonic impedance of the single-tuned LC filter $Z_{C K}$ is given as:

$$
\mathrm{Z}_{\mathrm{CK}}=\mathrm{R}+\mathrm{j}\left(\mathrm{KX}_{\mathrm{L}}-\frac{\mathrm{X}_{\mathrm{C}}}{\mathrm{K}}\right)
$$

where $R$ is the compensator resistance in ohms. $K X_{L}$ and $X_{C} / K$ represents the $K$ th inductive and capacitive reactance of the passive filter in ohms, respectively.

Consequentially, following the basic circuit analysis, one can determine the $K$ th harmonic supply current $I_{\mathrm{SK}}$ and its root-mean-square (rms) value $I_{S}$ in ampere, and the $K$ th harmonic load voltage $V_{\mathrm{LK}}$ its rms value $V_{L}$ in volt, as follows:

$$
\begin{aligned}
& \mathrm{I}_{\mathrm{SK}}=\frac{\left[\beta_{1 \mathrm{~K}}\right]+\mathrm{j}\left[\beta_{2 \mathrm{~K}}\right]}{\left[\alpha_{1 \mathrm{~K}}\right]+\mathrm{j}\left[\alpha_{2 \mathrm{~K}}\right]} \\
& \mathrm{I}_{\mathrm{S}}=\sqrt{\sum_{\mathrm{K}} \mathrm{I}_{\mathrm{SK}}^{2}}
\end{aligned}
$$

and

$$
\begin{aligned}
& \mathrm{V}_{\mathrm{LK}}=\frac{\left[\lambda_{1 \mathrm{~K}}\right]+\mathrm{j}\left[\lambda_{2 \mathrm{~K}}\right]}{\left[\alpha_{1 \mathrm{~K}}\right]+\mathrm{j}\left[\alpha_{2 \mathrm{~K}}\right]} \\
& \mathrm{V}_{\mathrm{L}}=\sqrt{\sum_{\mathrm{K}} \mathrm{V}_{\mathrm{LK}}^{2}}
\end{aligned}
$$

where

$$
\begin{aligned}
& \mathrm{A}_{\mathrm{K}}=\mathrm{R}_{\mathrm{TK}} \mathrm{R}_{\mathrm{LK}}-\mathrm{X}_{\mathrm{LK}} \mathrm{X}_{\mathrm{TK}}, \\
& \mathrm{B}_{\mathrm{K}}=\mathrm{R}_{\mathrm{LK}} \mathrm{X}_{\mathrm{TK}}+\mathrm{R}_{\mathrm{TK}} \mathrm{X}_{\mathrm{LK}}, \\
& \mathrm{X}_{\mathrm{K}}=\mathrm{KX}_{\mathrm{L}}-\frac{\mathrm{X}_{\mathrm{C}}}{\mathrm{K}}, \\
& \mathrm{C}_{\mathrm{K}}=\mathrm{RR}_{\mathrm{LK}}-\mathrm{X}_{\mathrm{LK}} \mathrm{X}_{\mathrm{K}}, \\
& \mathrm{D}_{\mathrm{K}}=\mathrm{RX}_{\mathrm{LK}}+\mathrm{R}_{\mathrm{LK}} \mathrm{X}_{\mathrm{K}}, \\
& \beta_{1 \mathrm{~K}}=\mathrm{V}_{\mathrm{SK}}\left(\mathrm{R}+\mathrm{R}_{\mathrm{LK}}\right)+\mathrm{I}_{\mathrm{LK}} \mathrm{C}_{\mathrm{K}}, \\
& \beta_{2 \mathrm{~K}}=\mathrm{V}_{\mathrm{SK}}\left(\mathrm{X}_{\mathrm{LK}}+\mathrm{X}_{\mathrm{K}}\right)+\mathrm{I}_{\mathrm{LK}} \mathrm{D}_{\mathrm{K}}, \\
& \lambda_{1 \mathrm{~K}}=\mathrm{V}_{\mathrm{SK}} \mathrm{C}_{\mathrm{K}}-\mathrm{I}_{\mathrm{LK}}\left(\mathrm{RA}_{\mathrm{K}}-\mathrm{B}_{\mathrm{K}} \mathrm{X}_{\mathrm{K}}\right), \\
& \lambda_{2 \mathrm{~K}}=\mathrm{V}_{\mathrm{SK}} \mathrm{D}_{\mathrm{K}}-\mathrm{I}_{\mathrm{LK}}\left(\mathrm{RB}_{\mathrm{K}}+\mathrm{A}_{\mathrm{K}} \mathrm{X}_{\mathrm{K}}\right), \\
& \alpha_{1 \mathrm{~K}}=\mathrm{A}_{\mathrm{K}}-\mathrm{X}_{\mathrm{K}}\left(\mathrm{X}_{\mathrm{LK}}+\mathrm{X}_{\mathrm{TK}}\right)+\mathrm{R}\left(\mathrm{R}_{\mathrm{TK}}+\mathrm{R}_{\mathrm{LK}}\right), \\
& \alpha_{2 \mathrm{~K}}=\mathrm{B}_{\mathrm{K}}+\mathrm{X}_{\mathrm{K}}\left(\mathrm{R}_{\mathrm{LK}}+\mathrm{R}_{\mathrm{TK}}\right)+\mathrm{R}\left(\mathrm{X}_{\mathrm{TK}}+\mathrm{X}_{\mathrm{LK}}\right) .
\end{aligned}
$$

The time-varying transmission loss (TL) is given as $\mathrm{TL}=\sum_{\mathrm{K}} \mathrm{I}_{\mathrm{SK}}^{2} \mathrm{R}_{\mathrm{TK}}$

Also, the time-varying load power factor $(\mathrm{PF})$ is given as

$$
\mathrm{PF}=\frac{\sum_{\mathrm{K}} \mathrm{G}_{\mathrm{LK}} \mathrm{V}_{\mathrm{LK}}^{2}}{\sqrt{\sum_{\mathrm{K}} \mathrm{I}_{\mathrm{SK}}^{2} \sum_{\mathrm{K}} \mathrm{V}_{\mathrm{LK}}^{2}}}
$$

Equations (11) and (12) show the two objective functions. Their expressions involving the primary variables which are the parameters of the proposed compensator $\left(R, X_{L}\right.$ and $\left.X_{C}\right)$. However, before we commence analyzing the objective functions to determine the optimum size of the passive filter which achieves the two desired criteria; it is essential to define the conditions constrained them. Particularly, in this study, there are two main non-linear constraints: the resonance constraint and the operator's typical values of the shuntconnected power capacitors based on IEEE Standard 18-2012.

Regarding the resonance constraint; it determines the $L$ and $C$ values, or the inductive-capacitive reactance that may resonate the system. Moreover, it can be determined by equating the imaginary component of the impedance $Z_{T H K}$ seen from the load side to zero and simplifying as given in (13). Hence, solving the resulted quadratic equation; its solutions will indicate the regions of the values of $X_{L}$ and $X_{C}$ that should be overstepped in the selection of the filter size to prevent the occurrence of resonance. 


$$
\begin{aligned}
& \operatorname{Im}\left\{\mathrm{Z}_{\mathrm{THK}}\right\}=0, \\
& \operatorname{Im}\left\{\frac{\mathrm{Z}_{\mathrm{CK}} * \mathrm{Z}_{\mathrm{LK}}}{\mathrm{Z}_{\mathrm{CK}}+\mathrm{Z}_{\mathrm{LK}}}+\mathrm{Z}_{\mathrm{TK}}\right\}=0, \text { or } \\
& {\left[\begin{array}{l}
{\left[\mathrm{X}_{\mathrm{TK}}+\mathrm{X}_{\mathrm{LK}}\right]\left(\mathrm{KX}_{\mathrm{L}}-\frac{\mathrm{X}_{\mathrm{C}}}{\mathrm{K}}\right)^{2}+} \\
{\left[\begin{array}{l}
\left.\mathrm{R}_{\mathrm{LK}}^{2}+\mathrm{X}_{\mathrm{LK}}^{2}+2 \mathrm{X}_{\mathrm{LK}} \mathrm{X}_{\mathrm{TK}}\right]\left(\mathrm{KX}_{\mathrm{L}}-\frac{\mathrm{X}_{\mathrm{C}}}{\mathrm{K}}\right)+ \\
{\left[\mathrm{R}^{2} \mathrm{X}_{\mathrm{LK}}+\mathrm{X}_{\mathrm{TK}}\left[\left(\mathrm{R}+\mathrm{R}_{\mathrm{LK}}\right)^{2}+\mathrm{X}_{\mathrm{LK}}^{2}\right]\right.}
\end{array}\right]=0 .}
\end{array}\right]}
\end{aligned}
$$

Regarding the typical values of the shunt-connected power capacitors; IEEE Std. 18-2012 [17] illustrates the voltage level and the corresponding standard kvar ratings $Q_{C i}$ of the capacitors. In this study, each value of the kvar rating $Q_{C i}$ of the considered voltage, that is stated in the standard, is used to determine the corresponding value of the capacitive reactance of the filter $X_{C i}$, as shown in (14) and (15), respectively. Consequentially, this value is later substituted in Equation (13) to convert it into a one-variable problem with one unknown $X_{L}$. It should be mentioned that the resistance $R$ of the filter has been neglected as the quality factor is usually considered to be high enough in the initial passive filter design [6].

$$
\mathrm{Q}_{\mathrm{Ci}}=\left\{\mathrm{Q}_{\mathrm{Cl}}, \mathrm{Q}_{\mathrm{C} 2} \ldots \mathrm{Q}_{\mathrm{Cn}}\right\} \text {, for } \mathrm{i}=1,2,3 \ldots \mathrm{n}
$$

where $Q_{C n}$ is the maximum rating (kvar) that can be used with the considered voltage. It should be noted that these kvar values are manipulated as discrete values. Hence, one can use each $Q_{C i}$ value to compute the resultant $X_{C i}$ as follows:

$$
\mathrm{X}_{\mathrm{Ci}}=\frac{\mathrm{V}_{\mathrm{S} 1}^{2}}{\mathrm{Q}_{\mathrm{Ci}}}
$$

Accordingly, one can formulate the considered optimization problems as follows: that;

Objective function 1: Maximizing the load power factor, so

Maximize $P F=f_{1}\left(X_{C i}, X_{L}\right)$,

s.t.

$Q_{C i} \in\left\{Q_{C 1}, Q_{C 2} \ldots Q_{C n}\right\}$, for $i=1,2,3 \ldots n$

$X_{C i}, X_{L}$ are not a solution of (13).

Objective function 2: Minimizing the transmission loss, so that;

Minimize $T L=f_{2}\left(X_{C i}, X_{L}\right)$,

s.t.

$Q_{C i} \in\left\{Q_{C 1}, Q_{C 2} \ldots Q_{C n}\right\}$, for $i=1,2,3 \ldots n$

$X_{C i}, X_{L}$ are not a solution of (13).

\section{Problem Solution}

The two primary criteria (maximum $P F$ and minimum $T L$ ) are considered to be independent. Therefore, equating the two differential equations formed by each criterion with respect to the variables $\left(X_{C i}\right.$ and $\left.X_{L}\right)$ to zero, one can get the following:

$$
\left[\frac{\partial P F}{\partial X_{L}}\right] d X_{L}+\left[\frac{\partial P F}{\partial X_{C}}\right] d X_{C}=0
$$

$$
\left[\frac{\partial T L}{\partial X_{L}}\right] d X_{L}+\left|\frac{\partial T L}{\partial X_{C}}\right| d X_{C}=0
$$

$X_{C}$ and $X_{L}$ are manipulated as independent values; hence, the elements $d X_{C}$ and $d X_{L}$ are considered to be free or independent on each other; thus, one can reformulate (16) and (17) to become as follows:

$$
\begin{aligned}
& \frac{\partial P F}{\partial X_{L}}=0, \\
& \frac{\partial P F}{\partial X_{C}}=0 . \\
& \frac{\partial T L}{\partial X_{L}}=0, \\
& \frac{\partial T L}{\partial X_{C}}=0 .
\end{aligned}
$$

The optimization approach carried out by the search algorithm is explained in the following points.

- Pick the first value of $Q_{C i}$ of the particular voltage, as given in Equation (14).

- Calculate the corresponding $X_{C i}$, as given in Equation (15).

- Substitute the $X_{C i}$ value into the constraint of the resonance, given in (13), and the two objective functions.

- Calculate the corresponding value of $X_{L}$.

- Apply the Golden-Section algorithm to trace the local values of $X_{L}$. Such algorithm is selected due to its few steps and function evaluations.

- Let $i=i+1$, and repeat till $i=n$.

- Scan the results to find the global solution through the local solutions.

- Assess the other power quality indices and report the results.

\section{System STUdied AND RESUlTS}

The system under study is taken from [18] for a typical power system has a $150 \mathrm{MVA}_{\mathrm{SC}}$ short-circuit strength, supply voltage of $60 \mathrm{~Hz}, 4.16 \mathrm{kV}$ (2400 phase voltage). The system is serving a $5100 \mathrm{~kW}$ (maximum demand) and $4965 \mathrm{kvar}$ threephase loads, with a displacement power factor equals 0.765 lagging.

The notable part of the loading profile consists of induction motors; this affects the means of the cumulative distributions of the $K$ th harmonic load impedance. Also, other loads exist such as configurations of some transformers and various lamp categories (incandescent and discharge).

Besides, it is intended that the number of loads stimulated is steadily decreasing with time during the time period $T$ [15]. The case under study was prepared under the latter harmonic backgrounds:

\section{- Source harmonic voltages:}

The background harmonic voltages are alternating in time independently. The harmonic supply voltages are arbitrarily given as $5 \%$ at $K=5$, or $V_{S S}=5 \%, 3 \%$ at $K=7$, or $V_{S 7}=3 \%, 2 \%$ at $K=11$, or $V_{S I I}=2 \%$, and $1 \%$ at $K=13$, or $V_{S I 3}=1 \%$ [19]. 
Fig. 2 illustrates the $K$ th harmonic of the mains versus the normalized time (t/T) where $t$ is the time, and $T$ is the period.

\section{- Non-linear load harmonic currents}

The load current contains a fifth harmonic current of 33 amperes, a seventh harmonic current of 25 amperes, an eleventh harmonic current of 8 amperes, and a thirteenth harmonic current of 9 amperes, as randomly chosen [16].

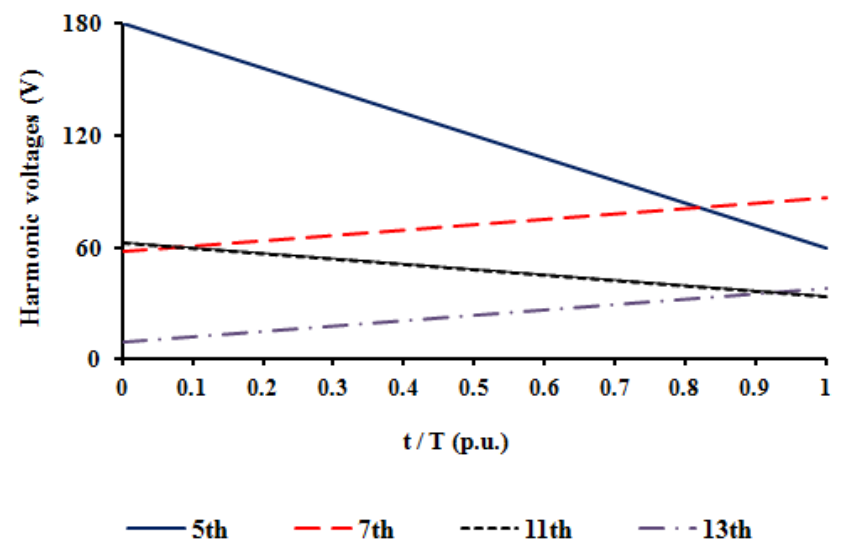

Fig. 2 Background harmonic voltages versus normalized time

- Load impedance $\left(Z_{L K}\right)$ :

Both load resistance and reactance are assumed timevarying values as given in Figs. 3-5, respectively.

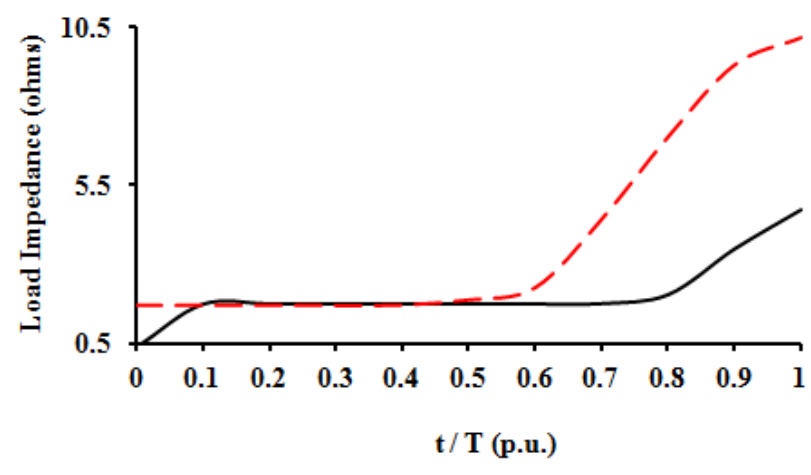

- Resistance $\quad--$ Reactance

Fig. 3 Equivalent load impedance at fundamental harmonic

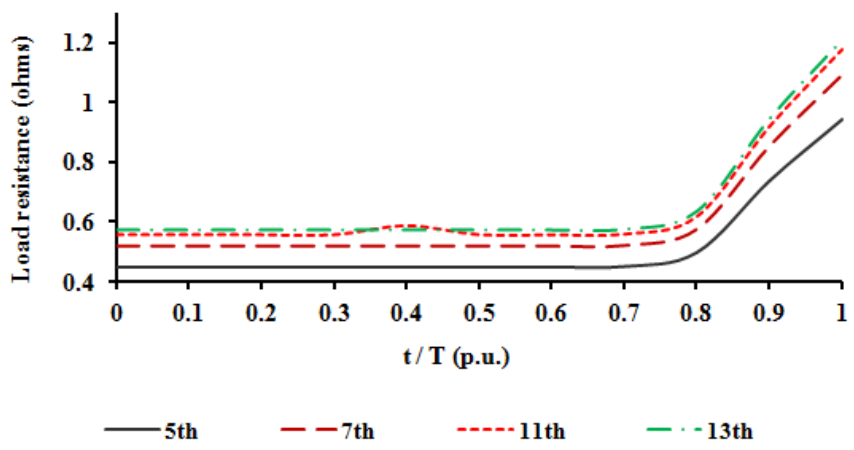

Fig. 4 The $K$ th equivalent load resistance

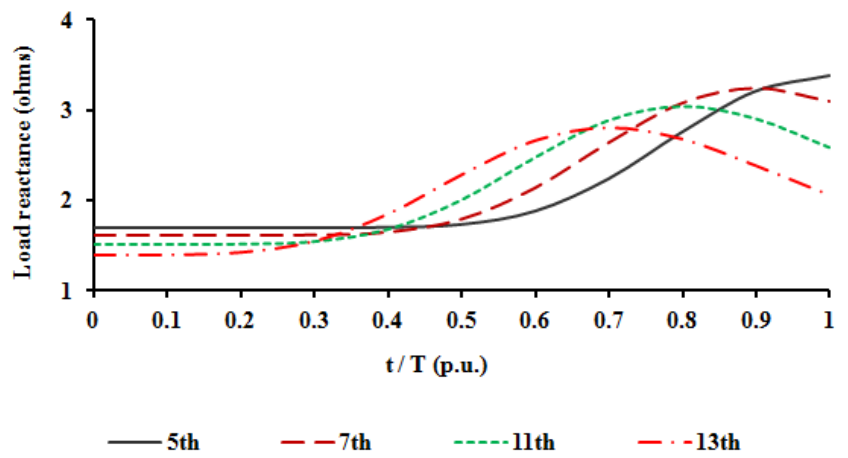

Fig. 5 The $K$ th equivalent load reactance

- Equivalent source (Thevenin) impedance:

Equivalent Thevenin impedance is assumed where the resistance $R_{T K}$ and reactance $X_{T K}$ are clarified in Figs. 6-8, respectively [15], so that

$$
\begin{aligned}
& \mathrm{R}_{\mathrm{TK}}=\mathrm{R}_{\mathrm{T} 1}=0.01154, \mathrm{X}_{\mathrm{T} 1}=10 \mathrm{R}_{\mathrm{T} 1}=0.1154, \\
& \mathrm{X}_{\mathrm{TK}}=\mathrm{KX}_{\mathrm{T} 1}\left[1+\mathrm{b}\left((\mathrm{t} / \mathrm{T})^{2}-0.25\right)\right] .
\end{aligned}
$$

where $b$ is a control variable ranging from 0 to $1[15]$.

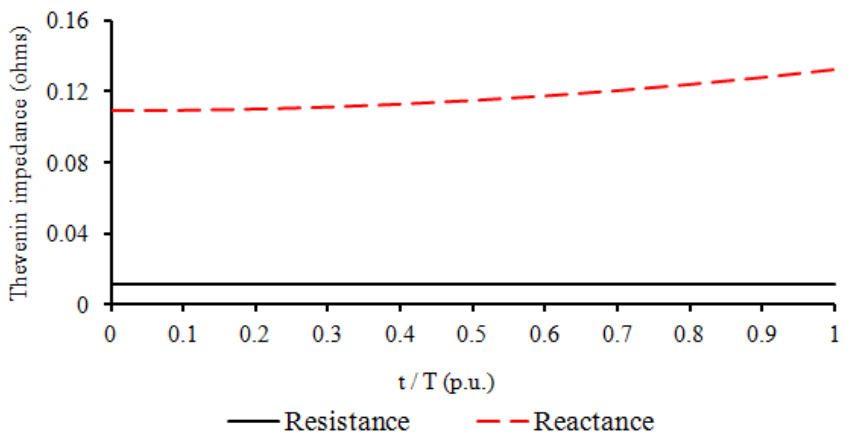

Fig. 6 Equivalent Thevenin impedance at fundamental harmonic

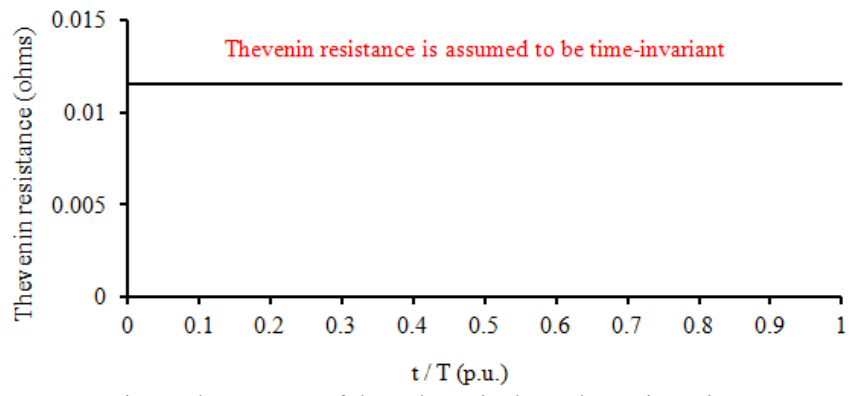

Fig. 7 The pattern of the $K$ th equivalent Thevenin resistance

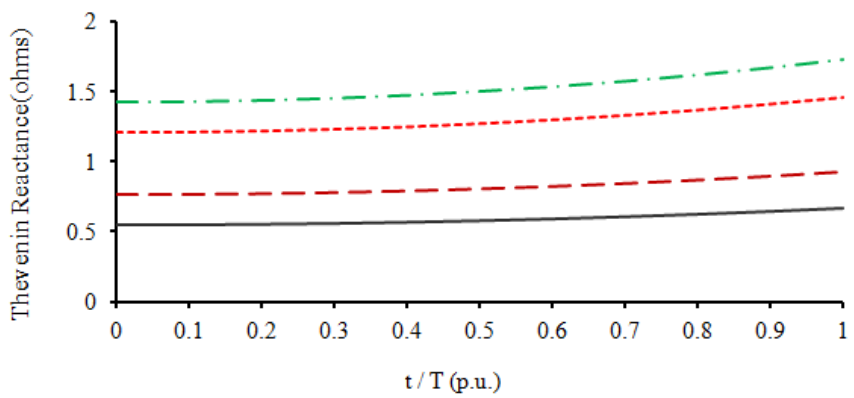

- 5th $\quad--7$ th $\quad----11$ th $\quad-\cdot-13$ th

Fig. 8 The pattern of the $K$ th equivalent Thevenin reactance 
- Results

The refined method is applied to the system given in Fig. 1; the exemplary arrangement is examined at discrete precise instants. Fig. 9 illustrates the pattern of the time-varying $P F$ in per-unit for both the compensated and uncompensated systems under minimum $P F$ criterion for various values of $b$.

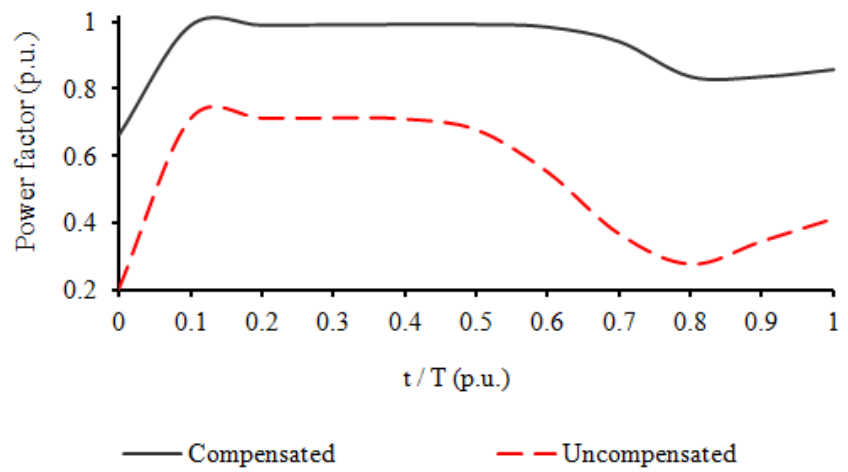

Fig. $9 P F$ in per-unit versus normalized time for various values of the variable $b$ for both compensated and uncompensated systems

Figs. 10 and 11 respectively show the time variation of the load classical $P F$ and the capacitor rating of the proposed passive filter under the effects of change of the Thevenin impedance by adjusting the value of the variable $b$ for the same criterion.

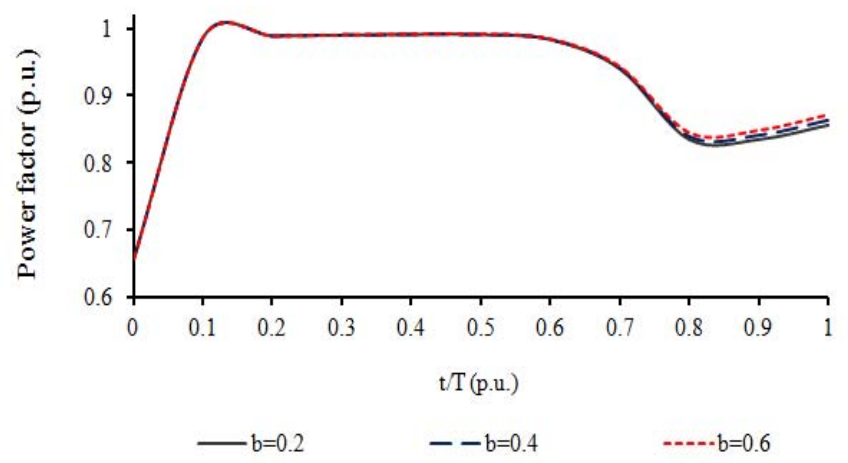

Fig. $10 P F$ in per-unit versus normalized time for various values of the variable $b$ under maximum power factor criterion

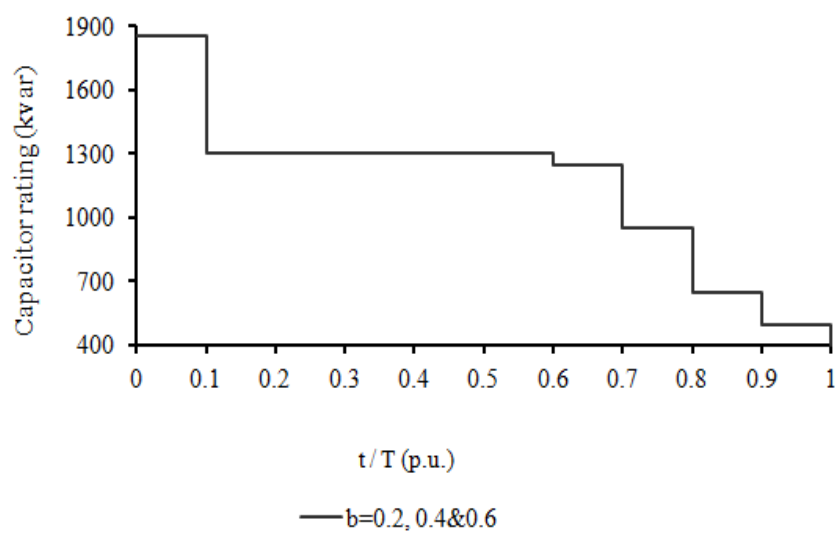

Fig. 11 Capacitor rating in kvar versus normalized time for various values of the variable $b$ under maximum power factor criterion
Fig. 12 illustrates the pattern of the time-varying $T L$ for both the compensated and uncompensated systems under minimum $T L$ criterion using various $b$ values.

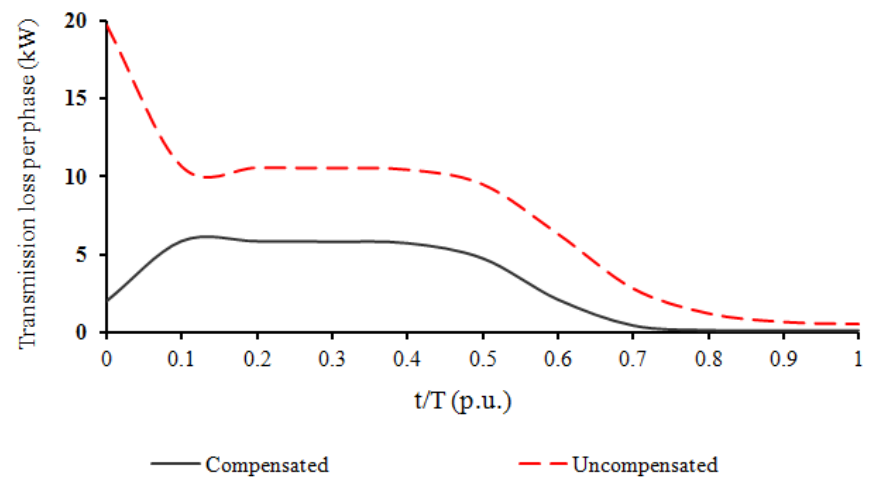

Fig. $12 T L$ per phase in kw versus normalized time using various $b$ values for both compensated and uncompensated systems

Figs. 13 and 14 respectively show the time variation of the $T L$ and the capacitor rating of the proposed passive filter under the effects of change of the Thevenin impedance by adjusting the value of the variable $b$ for the same criterion.

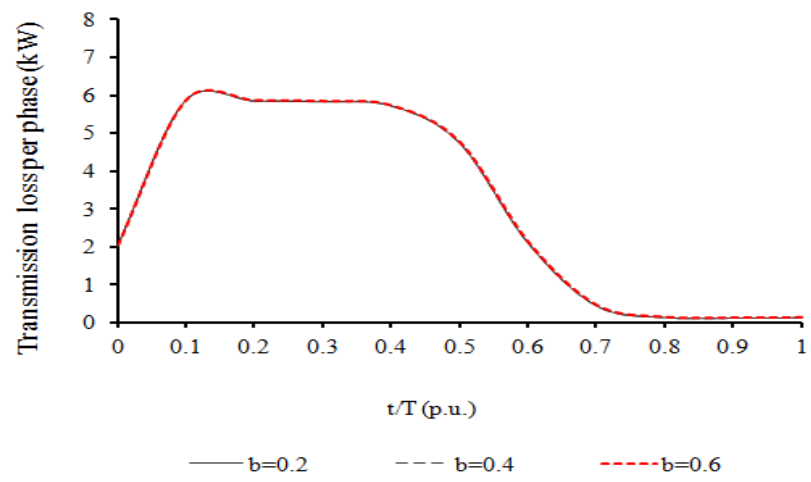

Fig. $13 T L$ per phase in kw versus normalized time using various $b$ values under minimum $T L$ criterion

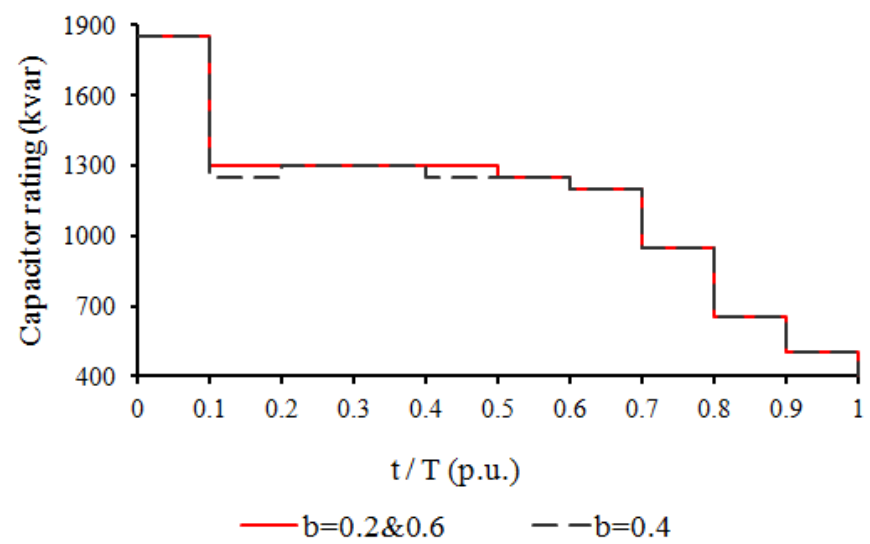

Fig. 14 Capacitor rating in kvar versus normalized time using various $b$ values under minimum $T L$ criterion 
Finally, the previous figures have shown that the given strategy is lowering the value of the line current; thus, reducing the transmission losses and increasing the transmission efficiency, while maintaining the desired load $P F$ at its acceptable limits $(>90 \%)$, compared with the corresponding simulation results without compensation [20].

\section{CONCLUSION}

The advance of non-linear loads has led to new challenges in the quality of power domain. Moreover, considering the time-varying nature of harmonic sources is a significant trend in the forthcoming power quality studies. In this work, the optimum sizing of multi-steps passive LC compensators for maximum power factor and minimum transmission loss for non-linear loads under time-varying conditions of background harmonic voltages, system impedance, and load impedance, is determined. The source harmonic voltages are considered varying in time independently of each other. The equivalent system impedance is given by varying the Thevenin impedance over a finite period. The functioning of the concerned filter is explained through a representative case study. Besides, the selection of the capacitor values is based on practically available (discrete) values in the markets. Simulation results illustrate the viability of the suggested approach. It is noticed the improvement occurs in the load power factor while minimizing the transmission loss and mitigating the harmonic distortion. Future works include studying the harmonic interaction phenomenon between the time-varying background harmonic voltages and the timevarying non-linear load currents. This implies adding voltage and current total harmonic distortion limits as additional constraints. Also, comparing the proposed filter design with other passive filter designs, under the same conditions, is under preparation.

\section{REFERENCES}

[1] I. F. Mohamed, S. H. E., Abdel Aleem, A. M. Ibrahim, and A. F. Zobaa, "Optimal Sizing of C-Type Passive Filters under Non-Sinusoidal Conditions," Energy Technology \& Policy, vol. 1, no. 1, pp. 35-44, 2014.

[2] A. F. Zobaa, S. H. E. Abdel Aleem, "A new approach for harmonic distortion minimization in power systems supplying nonlinear loads", IEEE Trans. Industrial Informatics, vol. 10, no. 2, pp. 1401-1412, 2014.

[3] S. H. E. Abdel Aleem, A. F. Zobaa, and A. C. M. Sung, "On the economical design of multiple-arm passive harmonic filters," 47 th International Universities' Power Engineering. Conf., UPEC'12, Uxbridge, Middlesex, United Kingdom, Sept. 4-7, 2012, pp. 1-6.
[4] A.F. Zobaa, M.M. Abdel Aziz, S.H.E. Abdel Aleem, "Comparison of shunt-passive and series-passive filters for DC drive loads", Electric Power Components and Systems, vol. 38, no. 3, pp. 275-291, 2010.

[5] A.F. Zobaa, "Maintaining a good power factor and saving money for industrial loads", IEEE Transactions Industrial Electronics, vol. 53, no. 2, pp. 710-711, 2006

[6] M.M.A. Aziz, E.E.A. El-Zahab, A.F. Zobaa, "LC compensators based on cost minimization for nonlinear loads", 2003 Large Engineering Systems Conference on Power Engineering, Montreal, Quebec, Canada, May7-9, 2003, pp. 143-147.

[7] A.F. Zobaa, M. Jovanovic, "A comprehensive overview on reactive power compensation technologies for wind power applications", 12th International Power Electronics and Motion Control Conference, EPEPEMC 2006. Portoroz, Aug. 30-Sept. 1, 2006, pp. 1848-1852.

[8] S. H. E. Abdel Aleem, M.T. Elmathana, A. F. Zobaa, "Different Design Approaches of Shunt Passive Harmonic Filters Based on IEEE Std. 5191992 and IEEE Std. 18-2002, " Recent Pat. Elec. Eng., vol. 6, no. 1, pp. 68-75, 2013.

[9] A. B. Nassif, W. Xu, and W. Freitas, "An investigation on the selection of filter topologies for passive filter applications," IEEE Trans. Power Del., vol. 24, no. 3, pp. 1710-1718, Jul. 2009.

[10]A.F. Zobaa, "Cost-effective applications of power factor correction for nonlinear loads", IEEE Transactions Power Delivery, vol. 20, no. 1, pp. 359-365, 2005

[11]J.C. Das, Power System Harmonics and Passive Filter Design, $2^{\text {nd }}$ ed. Wiley-IEEE Press, 2015.

[12] M.M. Abdel Aziz, E.E. Abou El-Zahab, A.M. Ibrahim, and A.F. Zobaa, "Practical considerations on power factor correction for nonlinear loads", 10th International Conference on Harmonics and Quality of Power, ICHQP'02, Rio de Janeiro, Brazil, Oct. 6-9, 2002, pp. 46-49.

[13]J.C. Churio-Barboza, J.M. Maza-Ortega, "Comprehensive design methodology of tuned passive filters based on a probabilistic approach," IET Generation, Transmission \& Distribution, vol. 8, no. 1, pp. 170-177, Jan. 2014.

[14]M. M. Abdel Aziz, A. M. Ibrahim, A. F. Zobaa, and A. M. Abdel Monem, "Effect of Time Variation of System Impedance and Voltage Harmonics on LC Compensation for Nonlinear Loads", 11th International Conference on Harmonics and Quality of Power, ICHQP'04, Lake Placid, New York, Sept. 12-15, 2004, pp. 77-82.

[15]A. F. Zobaa, A. Vaccaro, H. H. Zeineldin, A. Lecci, and A. M. Abdel Monem, "Sizing of passive filters in time-varying nonsinusoidal environments", 14th International Conference on Harmonics and Quality of Power, ICHQP'10, Bergamo, Sept. 26-29, 2010, pp. 1-8.

[16]M.M.A. Aziz, A.F. Zobaa, A.M. Ibrahim, A.M.A. Monem, "Effect of time variation of system impedance and voltage harmonics on LC compensation for nonlinear loads", IEE Proceedings-Electric Power Applications, vol. 153, no. 4, pp. 619-624, July 2006.

[17] IEEE Standard for Shunt Power Capacitors, IEEE Standard 18-2012, 2012.

[18] IEEE Recommended Practices and Requirements for Harmonic Control in Electrical Power Systems, IEEE Standard 519-1992, 1992.

[19] Voltage characteristics of the electricity supplied by public distribution systems, EN Standard 50160, 1994.

[20] Shady H.E. Abdel Aleem, Ahmed M. Ibrahim, and Ahmed F. Zobaa, "Harmonic assessment-based adjusted current total harmonic distortion", The Journal of Engineering, 2016. DOI: 10.1049/joe.2016.0002 